\title{
ANALYTICAL VIEW OF THE PERCEPTION OF SELECTED INNOVATIVE APPROACHES IN MARKETING COMMUNICATIONS
}

\author{
DOI: 10.12776/QIP.V19I1.441
}

\author{
PETER DORČÁK, PAVEL ŠTRACH, FRANTIŠEK POLLÁK
}

Received 2 September 2014, Revised 15 September 2014, Accepted 15 November 2014

\begin{abstract}
Purpose: The purpose of this paper is to present by means of thorough analysis of the selected market the perception of innovative approaches in marketing communication, both from the perspective of the companies on the supply side and from the perspective of their potential customers on the demand side. As regards the companies, it is in particular about their perception of relative benefits the use of electronic marketing instruments has given the degree of effort and resources spent on the establishment and maintenance of e-marketing infrastructure. As regards the customers, it is, in turn, about their perception of the particular aspects of use of virtual social networks by the companies for branding purposes or directly for promotion.
\end{abstract}

Methodology/Approach: Object of the research were real companies active on the analysed market. The subject of the research were their actual and potential customers represented by the users of one of the local Internet portals long active on the analysed market. Both these groups were presented with questions by means of electronic questionnaires. The data were subsequently processed and interpreted through cluster analyses.

Findings: Based on the confirmed aspects we came to the conclusion that perceived benefit of the Internet on business is closely related to on-line activity of the companies and to the number of instruments the company uses to promote its business. Last but not least, we have investigated whether economic status of the users (real or potential customers) has an impact on their perception of the companies' use of social networks for promotional purposes. The similarity of behaviour of particular groups allows for more accurate targeting of on-line activity with respect to selected target markets. 
Research Limitation/implication: The biggest limitation is the territorial nature of the research. Research was targeted primarily at the Central European market.

Originality/Value of paper: Presented partial results of the comprehensive research are based on empirical data collected from important samples of both sides of the analysed market, thus this paper as such may significantly contribute to the clarification of the issue of innovations in promotional mix in order to increase competitiveness or prosperity of SMEs active on the central European market.

Keywords: internet; social network; innovations; marketing communication

\section{INTRODUCTION}

Traditional marketing as we know it from the past has undergone substantial transformation in the past two decades. Technological innovations, and not least the Internet, have changed the traditional ground rules. Second half of the 20th century undoubtedly belonged to the radio and later the television, however, despite the fact that these media are still part of traditional communication mix used by most companies, they are gradually losing their impact on consumers' purchasing decisions or, in other words, their influence on the fundamental ability to capture attention of the target market. This view has been supported by Delina and Vajda (2006), Wierzbinski (2014). Today's world is different and it is necessary to adapt the method of managing marketing campaigns to this new setting. People are able to apprehend only fragments of messages presented to them and Google is becoming the answer to almost any question. Twenty years ago, front page article in American newspaper Time had about 4,500 words, nowadays it is only 2,800 words. An average length of a commentary in 1965 was 42 seconds compared to today's 8 seconds. This view has been supported by Van Der Bergh and Behrer (2012). According to current British researches, average consumer is "attacked" by more than thousand commercial messages per day. In the past, basic display of promotion was to forcefully promote one's product on target markets and the markets responded with a respective demand but this PUSH system seems to be less and less effective in today's hyperinformation times. Not only that there usually isn't expected demand, but also the advertising message often disappears in the information cluster of thousands of other messages. In such case any efficiency is lost and there is a need to significantly revise established communication mix. In this case, e-marketing communication mix may be an effective tool for targeted and personalized communication. This view has been supported by Dorčák and Pollák (2010), Szabo, Ferencz and Pucihar, (2013). 


\section{CURRENT STATE OF KNOWLEDGE OF THE ANALYSED ISSUE}

David Scott (2008) notes in his publication titled "New Rules of Marketing and PR" that before the emergence of the Internet companies basically had only two options how to attract the attention of the target market. The first option was buying expensive advertising space, the second one was getting media attention in different ways. The Internet has significantly changed these rules. Unlike traditional media, the Internet has enabled the companies to establish direct relationship with the customer. Internet as an interactive medium with dynamically growing number of users is currently the preferred environment for the execution of promotional activities. Promotion in this virtual environment is an effective instrument to address wide customer base, both in the short term (often even in real time) and for a fraction of the cost compared to traditional media. New marketing rules are reflected in practice in such way that by means of direct form of addressing the promotional message reaches groups of customers which have been previously overlooked for various reasons, especially because of mass targeting of traditional promotion. This perfect market coverage by finding and addressing those parts of the market which are under other circumstances rather latent rapidly increases the efficiency of resources spent on promotion. This view has been supported by Delina (2009), Delina and Tkáč (2010). Marketing on the Internet is not just a fashion trend, but also a significant evolutionary step forward. In domestic and foreign literature e-marketing is viewed from different angles. Stuchlík and Dvoráček (2000) define marketing on the Internet simply as the use of Internet tools for the performance and support of marketing activities. Chaffey and Ellis-Chadwick (2012) agrees with this claim and states that e-marketing is particularly about achieving companies' marketing objectives through the use of information technologies. According to scientific literature, it may be said that e-marketing uses basic marketing fundamentals and subsequently applies them in the virtual environment of the Internet. This view has been supported by Dorčák and Pollák (2010), Soviar and Vodák (2012). Janouch (2010) further notes that given the way of its use in marketing the Internet significantly contributed to the "customization", i.e. to the state where businesses are beginning to realize different and distinct needs of its customers and are adjusting the offer of their products, as well as forms of communication, to these needs. Therefore, if the companies do not want to lag behind in this increasingly competitive battle, they must follow the trends (in fact, they are directly forced to do so by the market) and find the best and most effective method to address and attract. This view has been supported by Sudzina and Kmec (2006), Lajčin, Frankovský and Štefko (2012), Zgodavova, Sutoova and Kisela (2015). The Internet undoubtedly offers one huge advantage; the possibility to address the customers at a moment when they perceive it as a helping hand. This view has been supported by Svetozarovova (2012); either by means of precise Internet presentation (website), web blog, elaborated and refined advertising or through currently very popular social networks. 
Because consumers - demand side - use electronic devices, pressure is created on the offer side. Organizations under market pressure are forced to adapt their communication channels so as to be able to quickly and efficiently display information on the screens of computers or ever more smaller screens of mobile devices. This view has been supported by Scott (2008). According to Krug (2014) for this purpose a responsive design can be created. According to Grant and Meadows (2012) the use of mobile wallets, mobile banking and mobile shopping is on the rise. Because many customers buy products online, providing a mobile application can improve their experience with a positive effect on the purchasing behaviour. This view has been supported by Jones (2011).

Based on the information in academic literature, as well as business practices we can say that electronic marketing is a certain degree of electronic commerce. This view has been supported by Varshney and Vetter (2002), Venkatesh, Ramesh and Massey (2003), Barnes and Scornavacca (2004), Bačík (2008), Saruc, Dorčák and Pollák (2013). However, in spite of the growing number of academic research, the overall summary on electronic marketing is not as consistent and somewhat fragmented. In geographical conditions of the Central European market this is a relatively new phenomenon. Available data come largely from research conducted mainly in Anglo-Saxon countries.

The Salesforce (2014) survey was carried out on a sample of 470 internet users, of which 265 used smartphones only, and the remaining 205 used smartphones tablets, etc. The data were collected between 15 December 2013 and 15 January $2014,85 \%$ of respondents of this survey replied that electronic devices are a central part of their daily lives. It is up to $90 \%$ within the age group $18-24,76 \%$ of smartphone users search for information using a mobile web browser. The survey found that $80 \%$ of internet users subscribe to a newsletter in order to get coupons, $63 \%$ of respondents can get such coupons following company profiles on social networks.

In January 2014, Inmar Organization (2014) conducted a survey of 1,091 respondents aged 18 to 69 years. According to the survey $66 \%$ of users, who expressed an interest in digital coupon, use smartphones, $44 \%$ of respondents would like to be able to submit a coupon when buying using a mobile phone, $39 \%$ of respondents would like to receive coupons for goods which they purchase regularly, directly on their mobile phones. The Ashraf and Kamal (2010) survey was conducted on a sample of 164 respondents from universities in Islamabad and Karachi. The data were collected between December 2009 and January 2010. The results of this survey say that innovativeness of consumers positively influences their attitude toward electronic marketing. Electronic devices are therefore accepted as a promotional medium.

\section{METHODOLOGY}

The aim of this paper is to present by means of thorough analysis of the selected market the perception of innovative approaches in marketing communication, 
both from the perspective of the companies on the supply side and from the perspective of their potential customers on the demand side. As regards the companies, it is in particular about their perception of relative benefits the use of electronic marketing instruments has given the degree of effort and resources spent on the establishment and maintenance of e-marketing infrastructure. As regards the customers, it is, in turn, about their perception of the particular aspects of use of virtual social networks by the companies for branding purposes or directly for promotion.

Object of the research were real companies active on the analysed market, their attitudes and perceptions of aspects related to the analysed issue. The subject of the research were their actual and potential customers represented by the users of one of the local Internet portals long active on the analysed market. As regards the organizations, primary research group comprised of the companies operating on the market in the Prešov region. The research sample approached in this research was the whole research group, i.e. more than 2,000 companies registered in the catalogue of the selected local information portal. The reason for choosing this research group was the fact that the companies registered in the catalogue of the selected local Internet portal represent, until the execution of the research task, a group of all organizations in the analysed area recognizable on the Internet. Only those organizations have been taken into account in the research of the possibilities of using innovative forms of promotion with an emphasis on virtual environment which are really visible in this virtual environment. As regards the users, primary group comprised of all registered users on the selected local Internet portal (by now it has almost 5,000 users). The approached research sample was again the whole primary group. Both these groups were presented with questions by means of electronic questionnaires (each group had its own questionnaire). The data were subsequently processed and interpreted through cluster analyses.

\section{EVALUATION AND DISCUSSION}

In the next subchapter we will interpret selected aspects of our research using the method of cluster analysis. The findings are equally analysed from the perspective of the companies, as well as from the perspective of their potential customers.

\subsection{Companies}

Investigating the perceptions of the benefits the Internet has on one's business with respect to on-line activity is very important factor in terms of the effectiveness in the use of resources to support this form of business. Internet as reactively new medium is still viewed as a complementary form of support of entrepreneurship. If the company decides to invest its time and resources into various support instruments of its business in the virtual world, it is desirable that the resulting effect on the organization is as positive as possible. Only in this way 
the Internet may in the future become number one choice for the companies in terms of their communication with the target market.

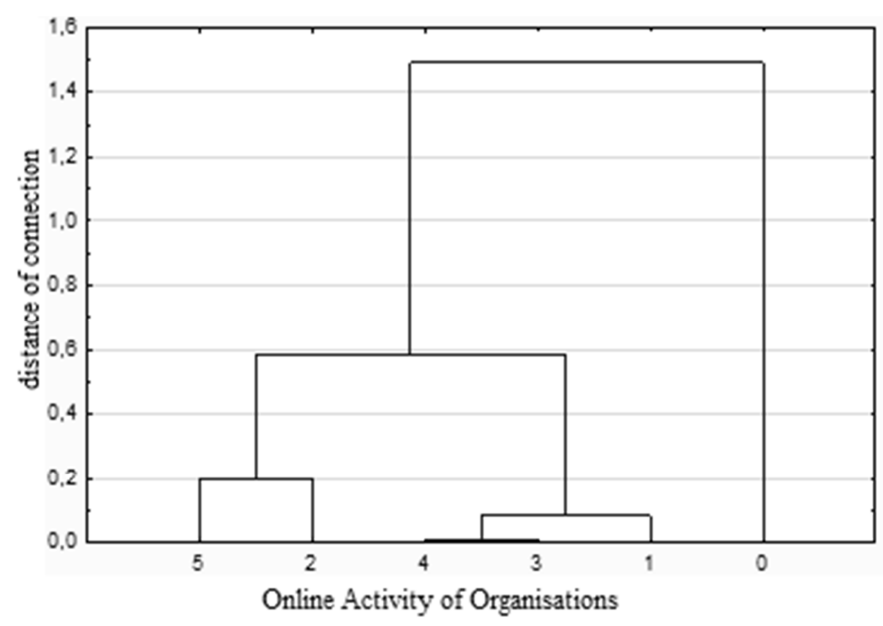

Figure 1 - Cluster analysis of companies' on-line activities

(Legend: 0 instruments, 1-1 instrument, 2 - 2 instruments, 3- 3 instruments, 4-4 instruments. 5 all of the instruments; These instruments were e.g.: website, e-shop, newsletter, profile in domestic web catalogue, profile in foreign web catalogue)

On-line activity of the companies is linked according to how they perceive the benefits of the Internet for their business. Thus, the $\mathrm{x}$ axis displays on-line activity of the organisation according to the number of instruments used to promote its business and the y axis indicates the degree of their dependence during linking. The smaller the distance of connection, the more alike is the perception of the benefits the Internet has on the company's business. The companies with the most similar perception of the benefits the Internet has their business are the companies which use 3 and 4 instruments and it can be seen that their perception of the benefits is almost identical. Next, the companies which use 3 and 4 instruments are linked with the companies which use only one instrument but their perception of the benefits is still relatively similar. Perception of the benefits is quite different among those companies who use 2 and 5 instruments which is rather interesting finding. The mentioned companies are further linked with the previous ones but the distance of connection is greater. Special category is comprised of organizations not using any instrument to support their business and their perception is, of course, quite different from other companies. This may be due to the fact that the respective organizations do not have experience with positive or negative benefits of the Internet and therefore cannot assess these benefits. Analysed aspects have been tested in parallel by means of Pearson chi-square test, which confirmed that the perceived benefit of the Internet on the business is directly related to on-line activity of the companies. 


\subsection{Customers}

Investigating users' (potential and real customers) perception of the use of social networks by the companies for promotional purposes with regard to their economic status is another interesting area within our research. The use of social networks has become almost daily part of the companies' business activities. The completed questionnaire survey showed that most companies either already have or plan to create a profile on one of the social networks. Therefore, we consider it necessary to analyse the perception of different economic groups of users. The similarity of behaviour of particular groups allows for more accurate targeting of on-line activity with respect to selected target markets.

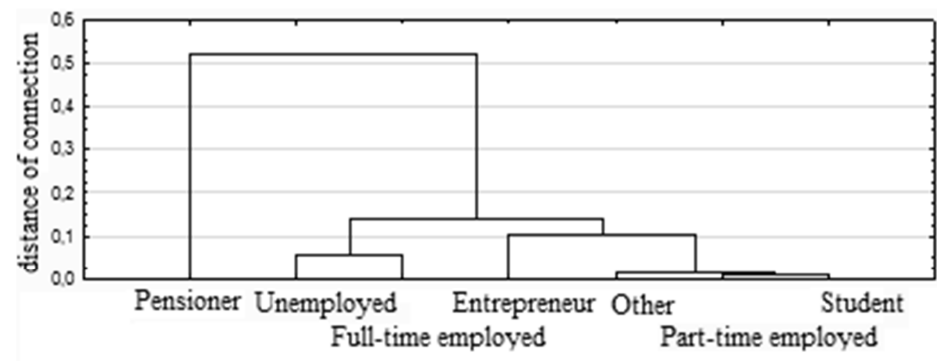

Figure 2 - Cluster analysis of the use of social networks

Economic status is linked according to how users perceive the use of social networks by the companies for promotional purposes. Thus, the $\mathrm{x}$ axis shows the economic status of the users and the $y$ axis indicates the degree of dependence while linking. The smaller the distance of connection, the more alike are the economic groups in their perception. The perception of the issue is most similar among students and part time employed and it can be seen that their attitude is almost identical. Similar attitude is shared among the respondents categorized as Other. Unemployed and full time employed share very similar opinion on the issue. Entrepreneurs have rather similar opinion as the already connected categories of Other, student and part time employed. Special category are the pensioners, their perception is quite far from the perception of other categories. This may be due to the fact that they do not have much experience or they do not use social networks in such extent. As can be seen, the perception of the use of social networks is quite different in individual economic groups. Again, analysed aspects were tested in parallel by means of Pearson chi-square test which confirmed that the perception of the use of social networks by the companies for promotional purposes is related to economic status of the user.

\section{CONCLUSION}

Slovak market is specific, whether in relation to external markets within Europe and the world, or within the internal markets. There are considerable regional 
differences between the West and the East of the republic (area of less than 500 kilometres). Companies active on the market are confronted with a relatively low purchasing power on the part of potential customers, while on the supply side (represented by potential competitors) the companies find themselves in a hypercompetitive environment. Analysed market on the supply side can be characterised by a high number of small businesses. Given their limitations, especially due to limited resources (human, financial, time ...), they must operate as efficiently as possible, if they want to maintain their presence on the turbulent and hyper-competitive market.

The issue of the use of e-marketing instruments in business is relatively little known in our geographical area. The companies are only gradually beginning to use the Internet and to profit from the opportunities it offers. Since this issue is relatively little examined, we considered it was important to look for the answers on basic questions formulated as research problems. Perception of the benefits of the Internet depending on the company's activities is an important indicator which shows the justification of spending often significantly limited resources on this type of business support. Statistical testing has confirmed that the perceived benefit of the Internet on the business is directly related to on-line activity of the organisations.

Based on the confirmed aspects we came to the conclusion that perceived benefit of the Internet on business is closely related to on-line activity of the companies and to the number of instruments the company uses to promote its business. Websites, e-shops, newsletters and profiles on domestic and foreign portals undoubtedly strengthen the identity of the organisation in virtual environment. A positive finding is that only $4.9 \%$ of the companies do not use any form of business support on the Internet. Another key finding is that almost $90 \%$ of the companies have their own website. We have assessed that a website as such is the basic pillar of virtual identity of the companies. Last but not least, we have investigated whether economic status of the users has an impact on their perception of the companies' use of social networks for promotional purposes.

By means of statistical testing we have come to a conclusion that the perception of the companies' use of social networks for promotional purposes is related to the economic status of the user. The use of social networks has become almost daily part of the companies' business activities. The completed questionnaire survey showed that most companies either already have or plan to create a profile on one of the social networks. Therefore, it was important to analyse the perception of the use of this form of promotion within various economic groups of users. The investigation has shown that the perception of the use of these networks is quite different in individual economic groups. The similarity of behaviour of particular groups allows for more accurate targeting of on-line activity with respect to selected target markets. 


\section{ACKNOWLEDGEMENT}

This article is one of the partial outputs of the current research grant VEGA no. 1/0145/14 entitled "Online Reputation Management (ORM) as a Tool to Increase Competitiveness of Slovak SMEs and its Utilization in Conditions of Central European Virtual Market".

\section{REFERENCES}

Ashraf, F., M. and Kamal, Y., 2010. Acceptance of mobile marketing among university students. Mustang Journal of Business and Ethics, 1, pp.9-29.

Bačík, R., 2008. Increase of the Competitiveness of Small and Medium Businesses in Prešov With the Assistence of Specific Marketing Instruments. In: Management 2008. In Times of Global Change and Uncertainty. Prešov: University of Prešov in Prešov, p. 189.

Barnes, S.J. and Scornavacca, E., 2004. Mobile Marketing: the Role of Permission and Acceptance. International Journal of Mobile Communication, 2(2), pp.128-139.

Chaffey, D. and Ellis-Chadwick, F., 2012. Digital Marketing: Strategy, Implementation and Practice. 5. ed., Pearson Education

Delina, R. and Tkac, M., 2010. The Impacts of Specific ICT Solutions on Productivity. In: Interdisciplinary Information Management Talks, IDIMT-2010, Information Technology - Human Values, Innovation and Economy. Linz: Trauner Verlag, pp.23-32.

Delina, R., 2009. Reputation building for electronic marketplaces. In: P. Mikulecký, T. Lišková and P. Čech, eds. 2009, Ambient Intelligence Perspectives, Volume 1, Amsterdam: IOS Press, pp.66-72.

Delina, R., Vajda. V., 2006. Teória a prax elektronického obchodovania. 1. ed. Košice: Elfa. (Slovak)

Dorčák. P. and Pollák, F., 2010. Marketing and e-Business: Ako sa zorientovat'v pojmoch a procesoch nového marketingu. 1. Vydanie. Prešov: EZO.sk, s.r.o. (Slovak)

Grant, A. and Meadows, H., 2012. Communication Technology Update and Fundamentals. Waltham: Focal Press.

Inmar, 2014. Coupon Trends: 2013 Year-End Report. [online]. Available at: http://go.inmar.com/rs/ inmar/images/Inmar_2014_Coupon_Trends_Report.pdf

Janouch, V., 2010. Internetový marketing: prosad'te se na webu a sociálních sítích. Brno: Computer Press. (Czech) 
Jones, M.T., 2011. The PayPall Official Insider Guide to Mobile Profit: Make money anytime, anywhere. Berkeley: Peachpit.

Krug, S., 2014. Don't Make Me Think Revisited: A Common Sense Approach to Web and Mobile Usability. San Francisco: New Riders.

Lajčin, D., Frankovský, M. and Štefko, R., 2012. Possibilities of Predicting the Behaviour of Managers When Coping with Demanding Situations in Managerial Work. Ekonomický časopis, 60(8), pp.835-853.

Salesforce. 2014. Mobile Behavior Report: Combining mobile device tracking and consumer survey data to build a powerful mobile strategy. [online]. Available at: http://www.exacttarget.com/sites/exacttarget/files/deliverables/ etmc2014mobilebehaviorreport.pdf

Saruc, N. T., Dorčák, P., Pollák, F., 2013. E-business and its Application in Conditions of Central European Market. Quality Innovation Prosperity, 17(1), pp.9-15.

Scott, D., M., 2008. Nové pravidlá marketingu a PR. 1. Ed. Brno: Zoner Press. (Czech)

Soviar, J. and Vodák, J., 2012. Value network as part of new trends in communication. Communications - Scientific letters of the University of Žilina, 14(2).

Stuchlík, P. and Dvořáček, M., 2000. Marketing na Internetu. 1. ed. Praha: Grada Publishing. (Czech)

Sudzina, F. and Kmec, P., 2006. The technological paradox and evaluation of the benefits of informatization. Ekonomický časopis, 54(3), pp.281-293. (Slovak)

Svetozarovova, N., 2012. Analysing the requirements of performance appraisal systems. In: Management 2012: research management and business in the light of practical needs. Prešov: Bookman.

Szabo, S., Ferencz, V. and Pucihar, A., 2013. Trust, Innovation and Prosperity. Quality Innovation Prosperity, 17(2), pp.1-8.

Van Der Bergh, J. and Behrer, M., 2012. Jak cool znacky ostávají hot. Praha: Albatros media. (Czech)

Varshney, U. and Vetter, R., 2002. Mobile Commerce: Framework, Applications and Networking Support. Mobile Networks and Applications, 7(3), pp.185-198.

Venkatesh, V., Ramesh, V. and Massey, A.P., 2003. Understanding usability in mobile commerce. Communications of the ACM, 46(12), pp.53-56.

Wierzbinski, B., 2014. Communication and information sharing in the process of creating market advantage among small and medium enterprises collaboration. In: Hradec Economic Days 2014. Hradec Králové: Gaudeamus, pp.437-445. 
Zgodavova, K., Sutoova, A., Kisela, M. 2015. Intelligent approaches for organisation's management system change: web based role play simulation environment. In: Total quality management - advanced and intelligent approaches: Proceedings: The 8th International Working Conference, 1st-5th June 2015, Belgrade, Serbia, pp.405-410.

\section{ABOUT THE AUTHORS}

Peter Dorčák is an associate professor at Goethe UNI Bratislava, Slovak Republic. His doctorate come from the University of Prešov in Prešov. His primary research topics include e-Business and customer behaviour. E-mail: peter@dorcak.com.

Pavel Štrach is an associate professor at ŠKODA AUTO University, Czech Republic. His doctorates come from the University of Economics in Prague and from University of Otago in New Zealand. Since 2007, Pavel Štrach has been an international visiting professor at IONA College, Hagan School of Business, New Rochelle, New York. His primary research topics include international strategies of companies, customer satisfaction, and marketing. E-mail: pavel.strach@fh-steyr.at

František Pollák is an lecturer at University of Prešov, Slovak Republic. His doctorate come from the University of Prešov in Prešov. His primary research topics include e-marketing, customer behaviour on internet and online reputation. E-mail: frank.pollak@acuityeng.com 